\title{
Functional Monomers and Polymers. XXXIX. Synthesis of Optically Active Poly(trans-2-methylpentadiene) by Asymmetric Inclusion Polymerization in Deoxycholic Acid*
}

\author{
Mikiji Miyata and Kiichi Takemoto \\ Department of Petroleum Chemistry, Faculty of Engineering, \\ Osaka University, Suita 565, Japan. \\ (Received November 18, 1976)

\begin{abstract}
KEY WORDS $\gamma$-Irradiation / Asymmetric Inclusion Polymerization / Deoxycholic Acid / Optically Active Polymer / Poly(trans-2-methylpentadiene) /
\end{abstract}

Inclusion polymerization is one of the unique polymerization techniques used in the solid state to prepare stereoregular polymers, particularly optically active diene polymers. In 1967 , Farina, et al., ${ }^{1}$ reported on the first asymmetric inclusion polymerization of trans-penta-1,3-diene using chiral perhydrotriphenylene as the host molecule. Very recently, Audisio, et al., ${ }^{2}$ studied the inclusion asymmetric polymerization of penta-1,3dienes in deoxycholic acid $(3 \alpha, 12 \alpha$-dihydroxy$5 \beta$-cholan-24-oic acid, I). The natural steroidal<smiles>CC(CCC(=O)O)C1CCC2C3CC[C@H]4CC(O)CC[C@]4(C)C3C[C@H](O)C12C</smiles>

I

acid in question is a chiral molecule and forms stable inclusion compounds with a variety of organic substances, ${ }^{3}$ including vinyl and diene monomers; ${ }^{4,5}$ the polymerization of these monomers included in the deoxycholic acid canal was comprehensively studied..$^{4-7}$

In this communication, we wish to describe the first synthesis of the optically active polymer, poly(trans-2-methylpentadiene), from its prochiral monomer, trans-2-metylpenta-1,3-diene, by asymmetric inclusion polymerization using deoxycholic

\footnotetext{
* For Part 38 of this series, see ref 7 .
}

acid as the host molecule. It is worth noting that the polymer thus prepared showed a substantially higher optical rotation than the rotations of other usual synthetic vinyl and diene polymers hitherto known.

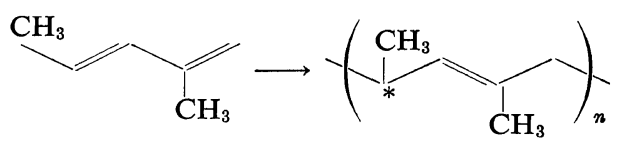

Commercially available deoxycholic acid was purified by repeated recrystallization from acetone. trans-2-Methylpenta-1,3-diene was a commercial reagent of pure grade (Aldrich Co.) and was used without further purification. The monomer-deoxycholic acid inclusion compounds were prepared as follows: $1.0 \mathrm{~g}$ of deoxycholic acid, $0.4 \mathrm{~m} l$ of trans-2-methylpenta-1,3-diene, and $2.5 \mathrm{~m} l$ of ethanol were placed in a glass tube of $12-\mathrm{mm}$ diameter, which was then sealed under vacuum $\left(1 \times 10^{-3} \mathrm{mmHg}\right)$ after three freeze-thaw cycles. The sealed tube was warmed to 70$80^{\circ} \mathrm{C}$ to give a homogeneous solution and then cooled gradually. Formation of the adducts was indicated by the appearance of small needle-like crystals. The tube was exposed to $\gamma$-irradiation from a $\mathrm{Co}^{60}$ source at $-196^{\circ} \mathrm{C}$ for $2 \mathrm{hr}$ with a dose rate of $3.0 \times 10^{5} \mathrm{rad} / \mathrm{hr}$. After the irradiation, the tube was warmed overnight at $50^{\circ} \mathrm{C}$ in order to allow the content to postpolymerize, and then cooled again to $-196^{\circ} \mathrm{C}$ and cut off. The content of the tube was immediately poured into excess methanol to separate deoxycholic acid from the polymer formed. The polymers thus 
obtained were washed with hot methanol thoroughly and dried under reduced pressure (18-mg yield).

The polymer which resulted melted at 159$164^{\circ} \mathrm{C}$ and was soluble in $o$-dichlorobenzene and tetralin. Its viscosity number $\left(\eta_{\mathrm{sp}} / c\right)$ in $o$-dichlorobenzene at $70^{\circ} \mathrm{C}$ was $0.26 \mathrm{~d} l / \mathrm{g}(c=0.20 \mathrm{~g} / \mathrm{d} l)$. IR and ${ }^{1} \mathrm{H}-\mathrm{NMR}$ spectra were found to be almost identical with those of poly(2-methylpentadiene) obtained by inclusion polymerization using racemic perhydrotriphenylene as the host molecule. $^{8}$

The polymer was found to show a high optical rotation of the same sign as that of deoxycholic acid itself $\left([\alpha]_{\mathrm{D}}=+55^{\circ}\right.$ in ethanol $):[\alpha]_{\mathrm{D}}=+250^{\circ}$; $[\alpha]_{577}=+290^{\circ} ; \quad[\alpha]_{546}=+350^{\circ} ; \quad[\alpha]_{435}=+560^{\circ} ;$ $[\alpha]_{365}=+940^{\circ}$ (measured at $26^{\circ} \mathrm{C}$ in $0.11 \times$ $10^{-3} \mathrm{~g} / \mathrm{m} l$ in $o$-dichlorobenzene solution). It is noteworthy that these specific rotation values are much higher than those of polypentadienes obtained either by inclusion or by coordination polymerization. That is, cis-1,4-polypentadiene obtained by inclusion polymerization in deoxycholic acid canal ${ }^{2}$ showed a specific rotation of $-21^{\circ}\left([\alpha]_{\mathrm{D}}\right.$ in toluene), and trans-1,4-polypentadiene obtained by the polymerization in chiral perhydrotriphenylene showed one of $+7.5^{\circ}$ $\left([\alpha]_{\mathrm{D}}\right){ }^{1,9}$ It should also be recalled that the coordination polymerization of these monomers gave polymers having specific rotation values of $+10^{\circ}$ to $-10^{\circ 10}$ and $-7.95^{\circ 11}$.

Thus, we obtained poly(trans-2-methylpentadiene) with high optical rotation by a radiationinduced canal polymerization technique, using deoxycholic acid as the host molecule. Studies of the polymerization behavior in detail, as well as of the properties of the polymers obtained, are now in progress.

\section{REFERENCES}

1. M. Farina, G. Audisio, and G. Natta, J. Am. Chem. Soc., 89, 5071 (1967).

2. G. Audisio and A. Silvani, J. Chem. Soc. Chem. Comm., 481 (1976).

3. W. C. Herndon, J. Chem. Educ., 44, 724 (1967).

4. M. Miyata and K. Takemoto, J. Polym. Sci. Polym. Lett. Ed., 13, 221 (1975).

5. M. Miyata and K. Takemoto, J. Polym. Sci. Polym. Symposia, in press.

6. M. Miyata and K. Takemoto, Angew. Makromol. Chem., 55, 191 (1976).

7. M. Miyata, K. Morioka, and K. Takemoto, $J$. Polym. Sci., Polym. Chem. Ed., in press.

8. M. Farina, G. Audisio, and M. T. Gramegna, Macromolecules, 5, 617 (1972).

9. M. Farina, Proc. Intern. Symp. Macromol. (Rio de Janeiro, 1974), 21 (1975).

10. G. Costa, P. Locatelli, and A. Zambelli, Macromolecules, 6, 653 (1973).

11. G. Natta, M. Farina, and M. Donnati, Makromol. Chem., 43, 251 (1961). 